Research Article

\title{
Risk Mitigation and Construction Control for Effective Underwater Recovery of an EPB Shield: A Case Study of the First Metro Tunnel in Tel Aviv
}

\author{
Weiqiang Qi, ${ }^{1}$ Zhiyong Yang $\left(\mathbb{D},{ }^{1}\right.$ Yusheng Jiang, ${ }^{1}$ Zhiyong Liu, ${ }^{1}$ Yinxin Guo, ${ }^{2}$ \\ and Xing Yang ${ }^{1}$ \\ ${ }^{1}$ School of Mechanics and Civil Engineering, China University of Mining and Technology-Beijing, Beijing 100083, China \\ ${ }^{2}$ China Railway 12th Bureau Group Co., Ltd, Taiyuan, Shanxi 030000, China \\ Correspondence should be addressed to Zhiyong Yang; yangzy1010@126.com
}

Received 9 January 2020; Revised 3 July 2020; Accepted 17 July 2020; Published 6 August 2020

Academic Editor: Dong Zhao

Copyright (C) 2020 Weiqiang Qi et al. This is an open access article distributed under the Creative Commons Attribution License, which permits unrestricted use, distribution, and reproduction in any medium, provided the original work is properly cited.

\begin{abstract}
Shield recovery in water-rich sand strata is a challenging issue in the field of shield tunnel engineering, especially when the end of the shaft cannot be reinforced by jet grouting or freezing or when the shield cannot be supported with a steel sleeve. Therefore, it is important to develop an effective recovery approach and adopt suitable techniques to control the risks. In this study, a new method based on filling the receiving shaft with water is proposed for the underwater recovery of an earth pressure balance (EPB) shield with zero end reinforcement from a metro tunnel in Tel Aviv, Israel. Several additional techniques are used to ensure safe recovery of the shield, including the design of a concrete cradle, drilling of pressure relief holes, control of excavation parameters, screw conveyor sealing, portal sealing, tail sealing, and grouting. Furthermore, according to the actual situation on site, filling the shaft with water to $1 \mathrm{~m}$ above the water level in the strata can prevent the fine sand from percolating into the shaft. Before the cutterhead approaches the underground diaphragm wall, the driving attitude should be strictly controlled, and the edge hob should be inspected for wear. The necessary thrust of shield tunneling in the underground diaphragm wall and shaft is calculated theoretically. In order to ensure the deformation control of the underground diaphragm wall and the smooth tunneling of the shield, the thrust of the shield excavating the underground diaphragm wall will not be larger than $12000 \mathrm{kN}$, and the penetration degree will be limited to $3 \mathrm{~mm} / r$. Qualitative observations and measurements of surface subsidence in the metro tunnel indicate that these risk mitigation techniques are effective and suitable for the underwater recovery of EPB shields in water-rich sand strata.
\end{abstract}

\section{Introduction}

Shield tunneling is an advanced technology that has been widely applied to the construction of metro tunnels [1-5]. Typically, the shield recovery process will encounter a wide range of rock types, such as loess, mixed, sandy cobble, soft, and water-rich sand strata. However, the mechanical instability of water-rich sandy strata can make shield recovery an extremely challenging part of the construction process, with serious consequences such as water seepage [6], sand inflow [7], and ground collapse [8]. Therefore, effective risk mitigation techniques are required to ensure the safe recovery of the shield from water-rich and sandy ground. A review of previous literature indicates that shield recovery technology in water-rich sandy strata predominantly includes artificial freezing [9], high-pressure rotary jet grouting [10], cement-soil deep mixing [11], and combinations of multiple approaches [12]. Another effective method for shield recovery in water-rich sandy strata involves covering the shield with a steel sleeve $[13,14]$.

Previously, recovery of the shield was typically performed using compressed air [15]; however, shield recovery in waterrich sandy strata currently involves reinforcement of the portal section $[16,17]$, commonly using cement treatment [18] or the freezing method. Some projects even use wide swaths of ground improvement during the recovery processes with a shaft that is backfilled and flooded $[19,20]$. Pan et al. [21] carried out a test of shaft end reinforcement for high permeability sandy soil, introduced a construction measure 
that would combine triaxial mixing piles with the freezing method, and successfully completed shield underwater recovery construction. Yang et al. [22] proposed a new type of reinforcement method combining portal sealing with the freezing method. To verify the feasibility of this method, they conducted full-scale field experiments to test the design of the experimental device, the experimental process, and the preparation of the experimental mud sample. Russo et al. [23] focused on the artificial ground freezing technique to ensure safe excavation of the large crown of a service tunnel in a silty sand layer and performed back analysis using numerical simulations. In order to guarantee the successful receiving of the shield in water-rich gravel stratum, Wu et al. [24] proposed the technology of vertical freezing reinforcement, synchronous grouting, external convex portal design, and portal chiseling. Yang et al. [25] conducted a case study of an artificially frozen end soil mass with a cup shape arrangement of horizontal freezing pipes via numerical analysis.

Thus, the majority of previous research studies have adopted freezing, cement-soil triaxial mixing piles, and highpressure jet grouting to solve the problems of water seepage and sand inflow during shield recovery in water-rich sandy strata. However, these reinforcement methods require a large site and a long construction period. This study focuses on a tunnel construction project in Tel Aviv, which is aiming to build the first metro tunnel in Israel. The space for reinforcing the end of the shaft is limited; therefore, the reinforcement method cannot be used for shield recovery. In addition, culturally important structures in the area adjacent to the receiving shaft require strict construction measures to be taken for their protection [26]. In this project, noise restrictions at night are extremely strict and lifting operations are subject to strict time limitations, resulting in a longer construction period. Accordingly, the complicated lifting operations required to install a steel sleeve cannot be used for shield recovery. Therefore, this study proposes a shield recovery method that involves filling the receiving shaft with water. This novel method is superior to both end reinforcement and steel sleeve methods considering the construction restrictions of this project. This study therefore contributes to reducing the risk of underwater shield recovery by proposing a fast and effective control method.

\section{Project Overview}

The Red Line light rail is the first subway to be built in Tel Aviv, Israel. The eastern section of the Red Line has been constructed by two earth pressure balance (EPB) tunnel boring machines with a front shield diameter of $7510 \mathrm{~mm}$. The cutterhead of the shield machine is a panel with an opening ratio of $38 \%$ and bore diameter of $7550 \mathrm{~mm}$. A total of nineteen 17-inch double-edged disc cutters are arranged on the cutterhead. In addition, 120 cutting knives, 16 tearing knives, 16 edge scrapers, and 1 central knife are arranged. Ben Gurion Station is the last stop on the eastern section of the Red Line and marks the point where the shield machines arrived at the receiving shaft, which was prepared for shield breakthrough and disassembly. However, the end of the shaft could not be reinforced because the traffic is heavy above the receiving shaft, surrounding houses are numerous, and the construction site is narrow. As the groundwater level outside the station was above the machine depth, a submerged breakthrough was planned. The water inside the shaft was designed to balance the water pressure in the surrounding ground, preventing water from flowing into the shaft. The internal dimensions of the receiving shaft are $22.0 \mathrm{~m} \times 23.15 \mathrm{~m}$. The top of the bottom slab is at $-9.05 \mathrm{~m}$ above sea level ( $\mathrm{m}$ a.s.l.), corresponding to a depth of $25.24 \mathrm{~m}$ from the surface. The tunnel axis is at $-4.815 \mathrm{~m}$ a.s.l., corresponding to a depth of $21.005 \mathrm{~m}$ below the surface. The underground diaphragm wall is $1.2 \mathrm{~m}$ thick and is reinforced by B40 concrete. The scope of the tunnel portal is B40 fiberglass-reinforced concrete. The surrounding environment and plan of the shaft are shown in Figure 1.

The shield receiving shaft was constructed by the covered excavation and sequential method. There is an opening at the top slab measuring $16 \mathrm{~m} \times 8.5 \mathrm{~m}$ and situated above the second tunnel, which was used to dismantle the machines and remove the machine parts from the ground. If a steel sleeve had been adopted for shield recovery, the steel sleeve would have to be shifted to the designated recovery position in the first tunnel. After recovery, the entire shield would then have to be shifted to the lower part of the lifting port for shield removal. The entire construction process would be complicated, noisy, and lengthy; therefore, it was deemed inconvenient. Moreover, the excavation area and top of the tunnel are predominantly located within the sand layer, which has a large permeability coefficient, and the groundwater level is higher than the top of the tunnel. Owing to these difficulties, a method of injecting water into the shaft was proposed to recover the shield.

2.1. Hydrogeological Conditions. From top to bottom, the strata are fine sand, clayey sand, silty sand, and kurkar (or aeolianite). Pale yellow fine sand (SP) is poorly graded and contains up to $2 \%$ subangular, hard kurkar gravel. Fine sand (SP-SC) is poorly graded with $5 \% \sim 12 \%$ silty clay and up to $5 \%$ subangular, hard kurkar gravel. Clayey sand (SC) contains $12 \% \sim 40 \%$ low plasticity clay and up to $2 \%$ subangular, hard kurkar gravel. Red brown, silty, clayey sand (SC-CL) contains more than $40 \%$ low plasticity clay and up to $5 \%$ subangular, hard kurkar gravel. The kurkar mainly consists of calcium carbonate and quartz and a small amount of cemented granular soil, which can be seen from the component analysis performed by electron microscopy (Figure 2). The kurkar can be subdivided into four categories; the highest-strength kurkar is termed $K-4$, whereas the layer with the lowest strength is termed $K-1$. Data from the closest borehole (ASI-10) to the shaft indicate that the stratum located within the tunnel excavation area is $K-1$. The geological profile and the kurkar strata are shown in Figure 3. For safety, the designated groundwater level is $1 \mathrm{~m}$ a.s.l. The distance between the top of the tunnel and the underground water level is $2.04 \mathrm{~m}$. The physical and mechanical parameters of each layer are shown in Table 1.

A total of 58 samples of $K-1$ were collected in the field. The particles were classified into size groups by the screening 


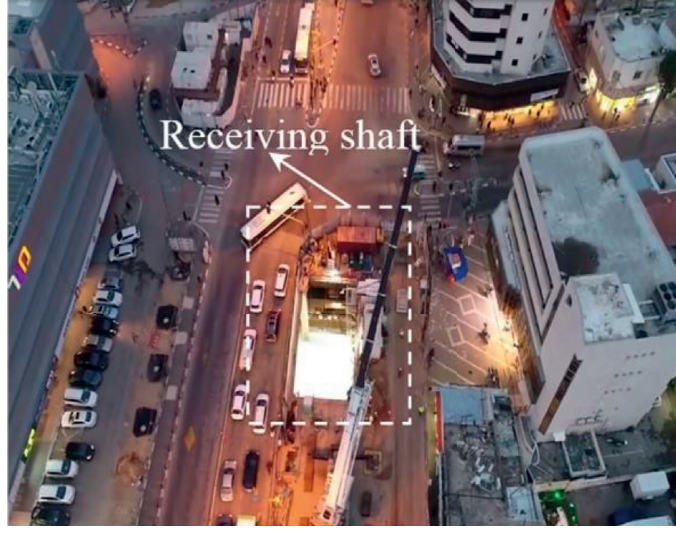

(a)

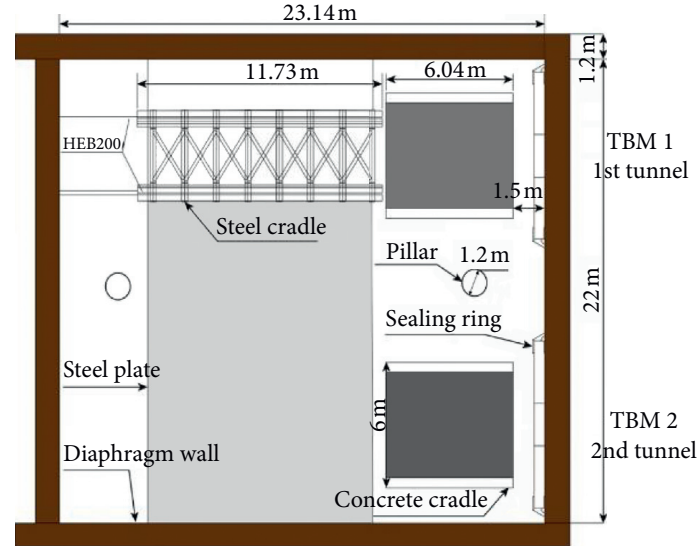

(b)

FIgURE 1: Illustrations of the receiving shaft: (a) the surrounding environment and (b) the design plan of the shaft.

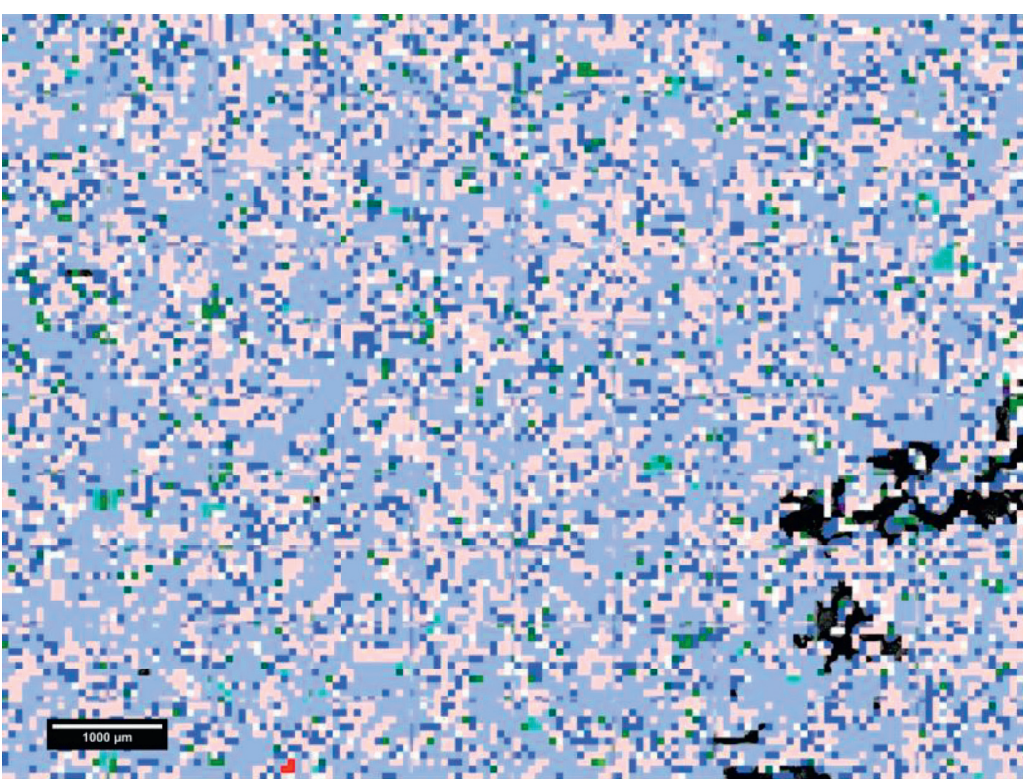

\begin{tabular}{|c|c|c|}
\hline Mineral & Mineral name & Vol. \% \\
\hline & Quartz & 29.89 \\
\hline & K-feldspar & 0.00 \\
\hline & Plagioclase $\mathrm{Fe}$ & 0.45 \\
\hline & Calcite & 53.02 \\
\hline & Dolomite & 0.00 \\
\hline & Anke rite & 15.17 \\
\hline & Illite/Muscovite & 0.00 \\
\hline & Illite/Sme ctite & 1.43 \\
\hline & Kaolinite & 0.01 \\
\hline & Chlorite & 0.00 \\
\hline & Biotite & 0.00 \\
\hline & Glauconite & 0.00 \\
\hline & Apatite & 0.00 \\
\hline & Pyrite & 0.00 \\
\hline & Side rite & 0.01 \\
\hline & Hematite & 0.00 \\
\hline & lime nite & 0.00 \\
\hline & Sphale rite & 0.00 \\
\hline & Anhydrite & 0.00 \\
\hline & Halite & 0.00 \\
\hline & Fluorite & 0.00 \\
\hline & Barite & 0.01 \\
\hline & Rutile & 0.02 \\
\hline & Zircon & 0.00 \\
\hline & Total & 30.34 \\
\hline & Total clays & 1.56 \\
\hline & Total carbonate & 68.07 \\
\hline & RoqFRAC & 98.44 \\
\hline
\end{tabular}

FIGURE 2: Component analysis of a partial kurkar sample.

method, and the mass fraction of each group was measured to obtain the percentage. The particle gradation curve shown in Figure 4 indicates that kurkar unit $K-1$ is mainly composed of fine sand to medium sand. The samples contain $0 \%$ to approximately $20 \%$ fine sand. Coarse sand and fine-tomedium gravel represent approximately $5 \%-40 \%$ of the particles in $K-1$.

2.2. Risk Analysis. When the water level outside the receiving shaft is higher than the buried depth of the shield tunnel in the sand strata and the steel sleeve or end reinforcement cannot be used, typical recovery technologies cannot guarantee the safety. In this situation, injecting water into the shaft to balance the water and soil pressure inside and outside the receiving shaft is the most effective method, but there are still many risks to be addressed. Based on the principle of water pressure balance, the theoretical water injection level in the shaft should be equal to the surrounding underground water level. The thickness of diaphragm wall is $1.2 \mathrm{~m}$; hence, the excavation gap is wide enough for sand to remain stable. In the absence of external force, the internal friction angle of the sand can help the sand to maintain stability in the gap. However, in order to prevent the cutterhead from disturbing the stratum when the shield machine breaks the diaphragm wall and to make the sand flow into the shaft, the water injection level in the shaft should be higher than the groundwater level. According to the actual construction situation, the more water is added, the better the resistance pressure effect in the shaft will be. In order to ensure the safety of the operation, the water level was raised to $1 \mathrm{~m}$ above the designated groundwater level, as 


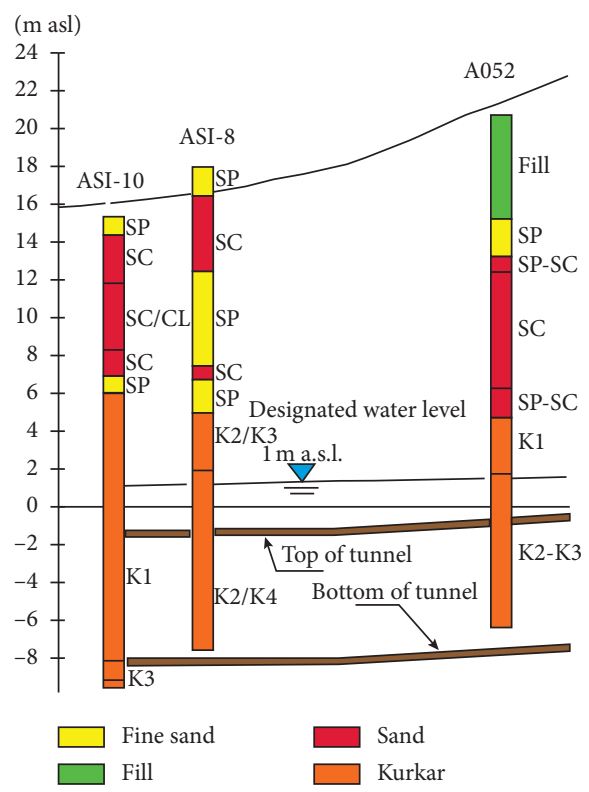

(a)

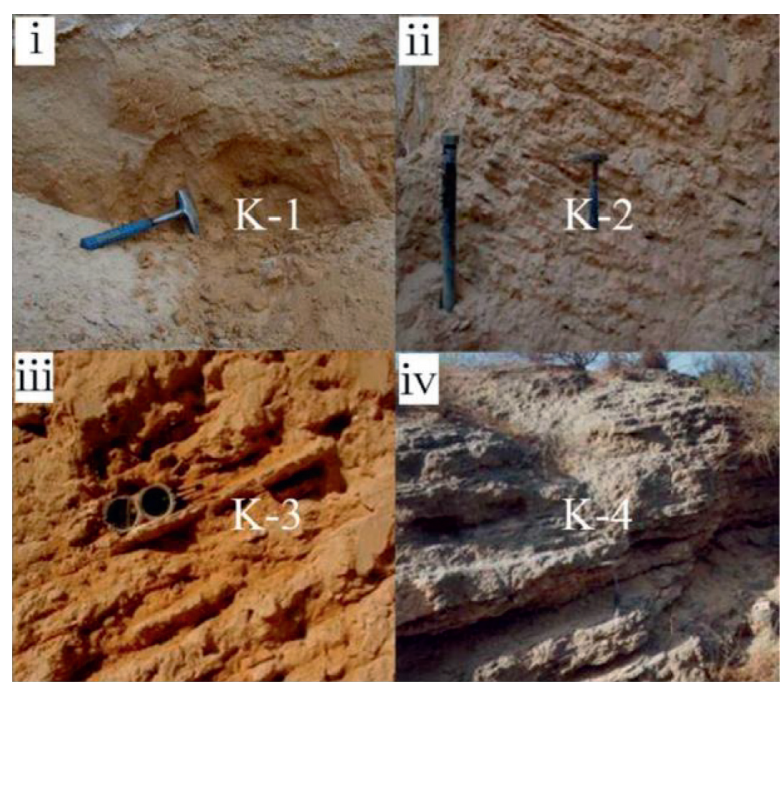

(b)

Figure 3: (a) Geological profile of the tunnel showing three exploration boreholes and (b) classification of kurkar strata in the tunnel area: (i) $K-1$, (ii) $K-2$, (iii) $K-3$, and (iv) $K-4$.

Table 1: Physical and mechanical parameters of strata in the tunnel area.

\begin{tabular}{lccccc}
\hline Soil name & Soil thickness $h(\mathrm{~m})$ & $\begin{array}{c}\text { Natural gravity } \gamma \\
\left(\mathrm{kN} / \mathrm{m}^{3}\right)\end{array}$ & Cohesion $c(\mathrm{kPa})$ & Internal friction angle $\varphi\left(^{\circ}\right)$ & $\begin{array}{c}\text { Permeability coefficient } \\
k(\mathrm{~m} / \mathrm{s})\end{array}$ \\
\hline Plain fill & 1 & 18.4 & 8 & 10 & $6 \times 10^{-6}-5 \times 10^{-5}$ \\
Fine sand (SP) & 1 & 19 & 0 & 35 & $5 \times 10^{-6}-5 \times 10^{-5}$ \\
Clayey sand (SC) & 2.5 & 20 & 10 & 20 & $5 \times 10^{-6}-5 \times 10^{-5}$ \\
Clayey sand (SC/CL) & 2.9 & 19 & 20 & 30 & $5 \times 10^{-6}-5 \times 10^{-4}$ \\
Fine sand (SC/SP) & 1.6 & 20 & 10 & 30 & $5 \times 10^{-6}-5 \times 10^{-4}$ \\
Fine sand (SP) & 1.2 & 19 & 28 & 35 & $5 \times 10^{-6}-5 \times 10^{-4}$ \\
Kurkar (K-1) & 14.2 & 19 & 30 & $5 \times 10^{-6}-5 \times 10^{-4}$ \\
\hline
\end{tabular}

shown in Figure 5. Before the cutterhead breaks through the underground diaphragm wall, the fine sand and water in the strata can only reach the front of the cutterhead and the chamber through the excavation gap. As the cutterhead breaks through the underground diaphragm wall, the water in the shaft will rush into the chamber through the opening of the cutterhead. The excavation gap at the bottom of the shield will be compacted by the heavy machine, but a gap will still exist between the upper half of the shield and the diaphragm wall, as shown in Figure 6. Throughout the construction process, the following risks exist:

(1) If the shield tail sealing fails, the water in the strata will seep into the tunnel, causing the tunnel to flood and the surface to collapse.

(2) If the screw conveyor sealing fails, there will be water gushing in the screw conveyor, resulting in a drop of water level in the shaft. The uneven pressure inside and outside the shaft will lead to seepage in the excavation gap and the water from outside will flow into the shaft and continuously remove fine sand, which will lead to ground collapse.
(3) If a large attitude deviation of the shield occurs, the shield will be unable to push the steel cradle.

(4) If the excessive thrust of the shield exceeds the bearing capacity of the underground diaphragm wall, the deformation of the underground diaphragm wall will be too large.

(5) If severe tool wear occurs, the underground diaphragm wall will not be excavated normally, causing the shield to get stuck in the underground diaphragm wall.

(6) If the portal sealing fails, when the water level in the shaft is lower than the water level in the strata, the fine sand in the strata will also flow into the shaft.

The environment around the surface of the shaft is complicated with heavy traffic and houses. If the surface collapses, a great accident will happen. Due to the proximity of traffic and houses to the site and the complexity of the surface environment, a collapse at the surface would have severe consequences. Therefore, appropriate risk mitigation and construction control measures are extremely important. 

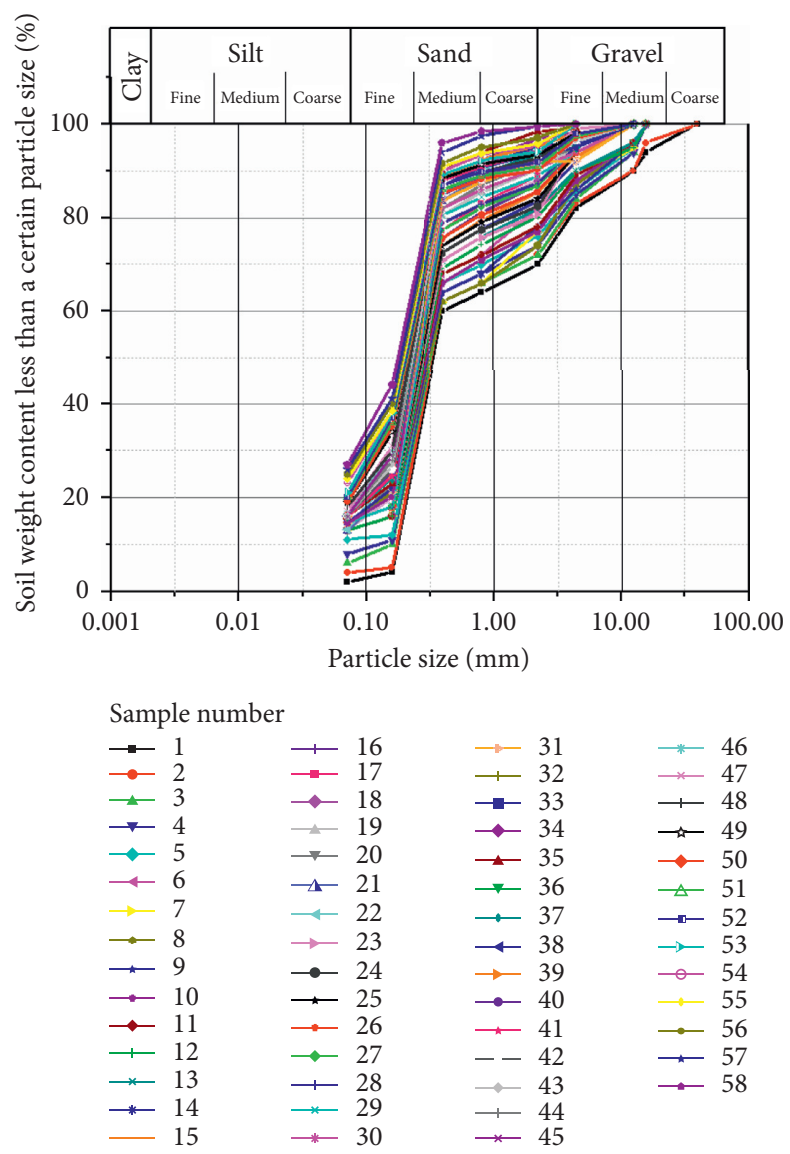

Figure 4: Particle gradation curve of the $K-1$ stratum.

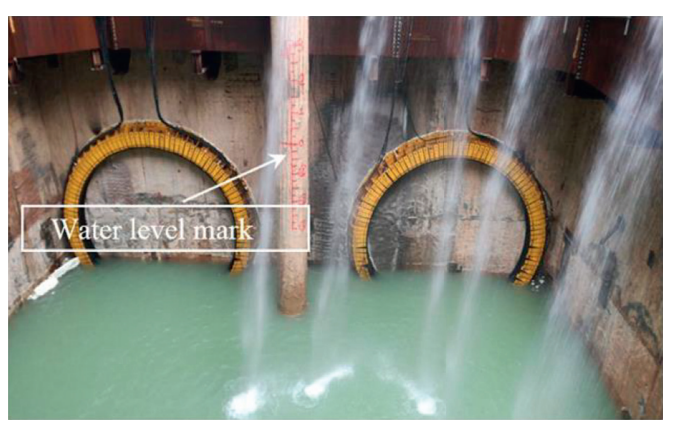

(a)

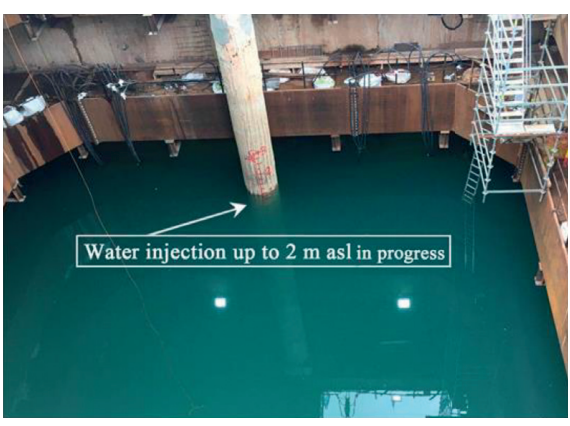

(b)

FIGURE 5: Water injection into the receiving shaft: (a) initiation of water injection and (b) water injection up to $2 \mathrm{~m}$ a.s.l. in progress.

\section{Force Balance Analysis of the Shield}

In order to ensure the smooth advance of shield tunneling in the underground diaphragm wall and receiving shaft, the necessary thrust of the shield is theoretically calculated, and the appropriate thrust range is determined in combination with the design bearing capacity of the underground diaphragm wall, both of which are detailed in Section 4.4. Finally, the actual shield thrust is used to verify the rationality of the calculation. The resistance in the flooded shaft during shield advance can be calculated as the sum of the water pressure on the front of the machine and the friction resistance between the machine and the soil, the diaphragm wall, or the supporting cradle. When calculating the breakthrough resisting force, the friction between the shield and diaphragm wall can be neglected, because it has little influence on the calculation range of shield thrust. The total length of the shield is about $11 \mathrm{~m}$, the underground diaphragm wall is only $1.2 \mathrm{~m}$, and the maximum contact between the shield shell and the underground diaphragm wall is $1.2 \mathrm{~m}$. Therefore, only $11 \%$ of the weight is distributed on the underground diaphragm wall. When the cutterhead breaks through the diaphragm wall, the friction coefficient between the shield 


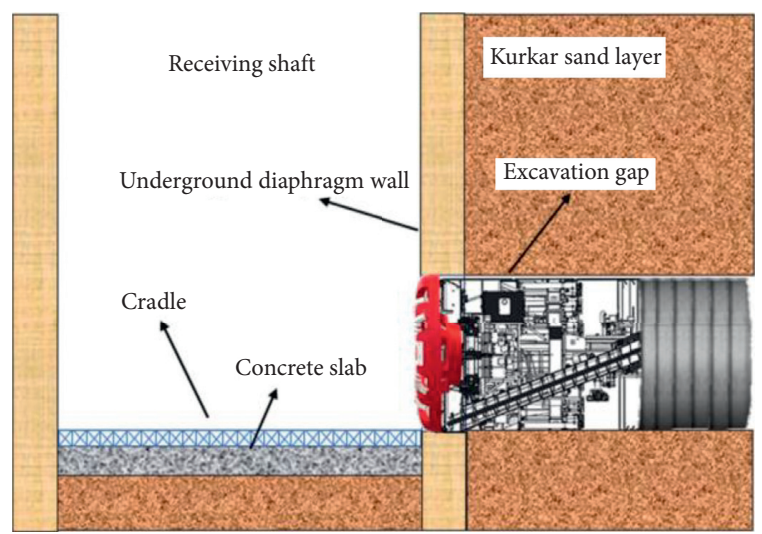

(a)

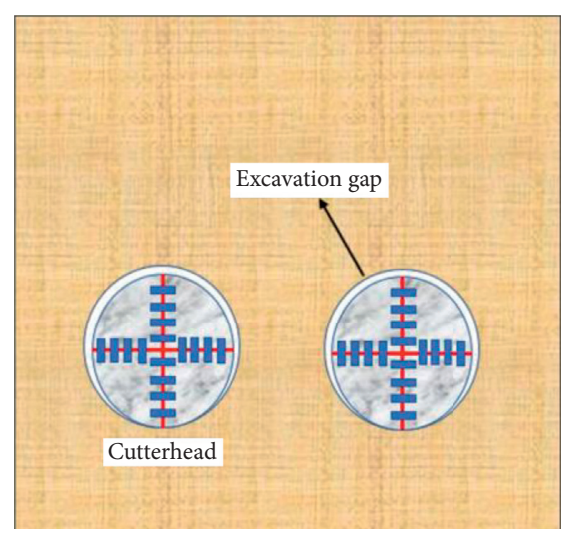

(b)

FiguRE 6: Schematic drawing of shield recovery in the shaft: (a) the shield breaking through the diaphragm wall and (b) the excavation gap.

and the diaphragm wall will not be much greater than that between the shield and the soil. Therefore, the approximate range of shield thrust can be determined only by calculating the friction of shield completely in the soil and the friction of shield completely on the bracket. Two situations were considered for the calculations: (1) when the cutterhead entered the shaft and (2) when the machine was fully inside the shaft, as shown in Figure 7.

3.1. Breakthrough Resisting Force. During the process of breakthrough (situation 1), the resistance during shield advance can be calculated as the sum of the water pressure on the front of the machine and the friction resistance between the shield and the soil. As the shield was not yet submerged in water, the buoyant force was not considered.

(1) Water Force. The hydraulic pressure on the shield can be regarded as an orthogonal cylinder pressure, with a length equal to the water pressure height on the tunnel axis. The water head height is the vertical distance between the water level and the tunnel axis. The force is obtained by multiplying the pressure height by the tunnel surface as follows

$$
E_{w}=\gamma_{w} \times Z_{w} \times S_{s}
$$

where $E_{w}$ is the water force, $\gamma_{w}$ is the unit weight of water, $Z_{w}$ is the vertical distance between the water level and the tunnel axis, and $S_{s}$ is the shield front area. The values of the parameters are as follows: $\gamma_{w}$ is $9.81 \mathrm{kN} / \mathrm{m}^{3}, Z_{w}$ is $6.815 \mathrm{~m}$, and $S_{s}$ is $44.75 \mathrm{~m}^{2}$. According to equation (1), $E_{w}$ is equal to $2991.77 \mathrm{kN}$.

(2) Friction Force. In this situation, the friction force is the resistance between the shield skin and the soil and is calculated as follows:

$$
E_{f 1}=\mu_{\text {soil }} \times W .
$$

where $E_{f 1}$ is the friction force; $\mu_{\text {soil }}$ is the frictional coefficient between the shield and the soil, which is
0.4 ; and $W$ is the weight of the front and middle shield, which is $3870 \mathrm{kN}$. According to equation (2), $E_{f 1}$ is equal to $1360 \mathrm{kN}$.

(3) Total Propulsion Resistance. The total breaking resistance is derived from the sum of the water pressure and friction as follows:

$$
E_{\text {total }}=E_{w}+E_{f 1} \text {, }
$$

where $E_{\text {total }}$ is the total propulsion resistance, and, according to equations (1) and (2), $E_{\text {total }}$ is equal to $4351.77 \mathrm{kN}$.

3.2. Resisting Force inside the Shaft. Once the shield is completely submerged (situation 2), the buoyancy must be considered. The water force will be the same as that during breakthrough and the friction force is the resistance between the shield surface and the receiving cradle, considering steel to steel friction. As the machine is submerged, the buoyant force must be subtracted from the total weight of the shield. The buoyant force is considered as the weight of water occupied by a cylinder with the same dimensions as the shield. The final friction force is as follows:

$$
\begin{gathered}
E_{b}=S_{s} \times L_{s} \times \gamma_{w} . \\
E_{f 2}=\mu_{\text {steel }} \times\left(E_{s}-E_{b}\right),
\end{gathered}
$$

where $E_{b}$ is the buoyancy force, $S_{s}$ is the shield front area, $L_{s}$ is the shield length $(11 \mathrm{~m}), \gamma_{w}$ is the unit weight of water $\left(9.81 \mathrm{kN} / \mathrm{m}^{3}\right), \mu_{\text {steel }}$ is the frictional coefficient between the shield surface and the receiving cradle $(0.2), E_{f 2}$ is the friction force, and $E_{s}$ is the total weight of the shield $(5430 \mathrm{kN})$. According to equations (4) and (5), $E_{b}$ is equal to $4828.97 \mathrm{kN}$ and $E_{f 2}$ is equal to $120.21 \mathrm{kN}$. The propulsion resistance required to build the last ring is the sum of water pressure and friction; thus, according to equation (3), $E_{\text {total }}$ is equal to $3111.98 \mathrm{kN}$.

3.3. Force from Gasket Compression. For safe and successful machine operation, a minimal ring build force is required. 


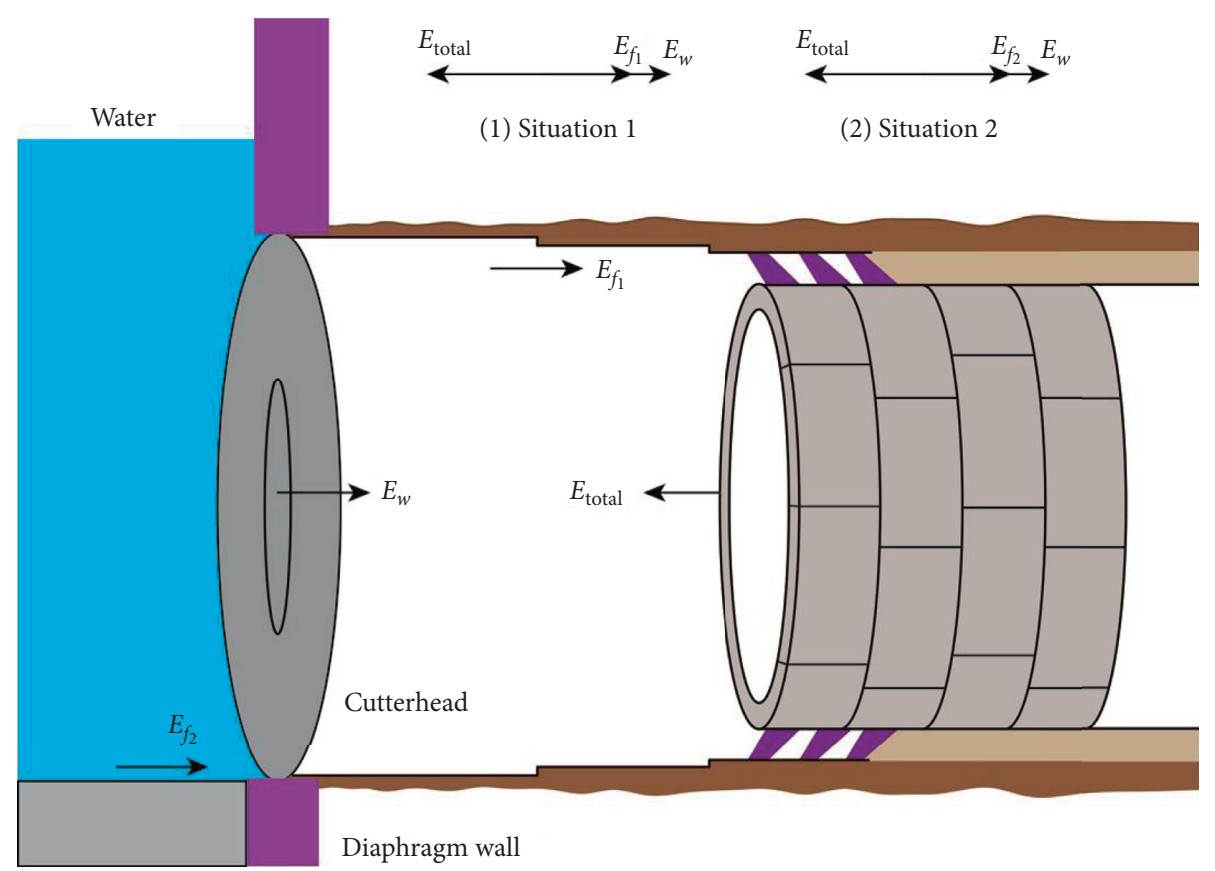

Figure 7: Schematic diagram of shield thrust calculation.

In addition, the compression on the gaskets should be high enough to provide effective sealing, thereby preventing water penetrating into the tunnel and enabling successful gap grout injection. The total force from the minimum gasket compression is as follows:

$$
\begin{aligned}
& C_{g}=D_{g} \times \pi . \\
& E_{g}=E_{\text {gu }} \times C_{g},
\end{aligned}
$$

where $C_{g}$ is the gasket circumference, $D_{g}$ is the gasket ring diameter $(7.52 \mathrm{~m}), E_{\mathrm{gu}}$ is the unit force from gasket compression (approximately $47.5 \mathrm{kN}$ ), and $E_{g}$ is the total force from gasket compression. According to equations (6) and (7), $C_{g}$ is equal to $23.62 \mathrm{~m}$ and $E_{g}$ is equal to $1122.18 \mathrm{kN}$.

3.4. Minimum Jacking Force for Ring Building. The necessary force applied during ring building to hold the segments in position before the ring is closed is

$$
E_{\mathrm{rb}}=E_{j} \times N_{j},
$$

where $E_{\mathrm{rb}}$ is the total force from the jacking force; $E_{j}$ is the unit force from jacking groups $(93.3 \mathrm{kN})$; and $N_{j}$ is the number of double jackings, which is 16. According to equation (8), $E_{\mathrm{rb}}$ is equal to $1492.8 \mathrm{kN}$.

\section{Risk Mitigation Techniques}

4.1. Design of Concrete Cradle. After the shield breaks through the underground diaphragm wall, the cutterhead will fall without support. If a steel cradle is directly installed, the shield may not be able to push up to the cradle without precise attitude control, and the shield body will become stuck in the diaphragm wall. More importantly, it is difficult to control the position of a steel cradle owing to buoyancy when water is added to the shaft. Therefore, a concrete cradle was proposed. In the concrete cradle design, as the shield breaks through the wall, the machine is initially supported by a concrete cradle comprised of two structural concrete blocks. The strength of concrete should not only withstand the weight of the shield machine without cracking but also be easy to be cut by the shield cutter. Israel has requirements for concrete strength and can only provide $\mathrm{B} 20$ concrete but no $\mathrm{B} 10$ or $\mathrm{B} 15$ concrete. The concrete is designed as low-strength concrete in the upper layer for shield excavation and high-strength concrete in the lower layer for bearing the weight of the shield. The grades of the upper and lower concrete are B20 and B30, respectively. The structural concrete blocks have a constant height and are topped by a thin concrete layer located on the bottom section of the shield; they are excavated as the cutterhead advances. The concrete cradle is $1.00 \mathrm{~m}$ high, $6.00 \mathrm{~m}$ wide, and $6.04 \mathrm{~m}$ long according to the size of the shield machine and the axis of the tunnel. It was situated $1.5 \mathrm{~m}$ from the underground diaphragm wall to allow displacement of the rubber seal installed on the wall. During the process of breakthrough, it had to accommodate a deviation of $\pm 50 \mathrm{~mm}$ to the machine theoretical position. Enabling the cutterhead to advance on the thin concrete provided the necessary tolerance for the machine position. The concrete cradle is illustrated in Figure 8. The concrete cradle is a temporary structure for the shield recovery. After the shield machine is dismantled, the concrete can be cut out with a small crushing hammer.

4.2. Pressure Relief Holes in the Portal Wall. When the shield reached the remaining $50 \mathrm{~cm}$ of the diaphragm wall, it stopped excavating, the screw conveyor was reversed, and 


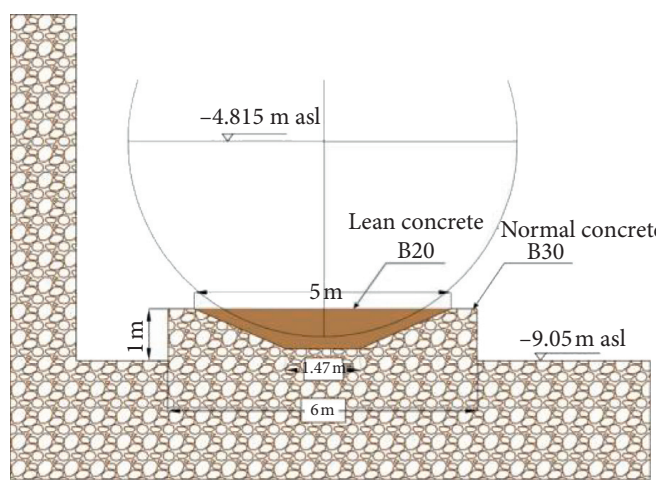

(a)

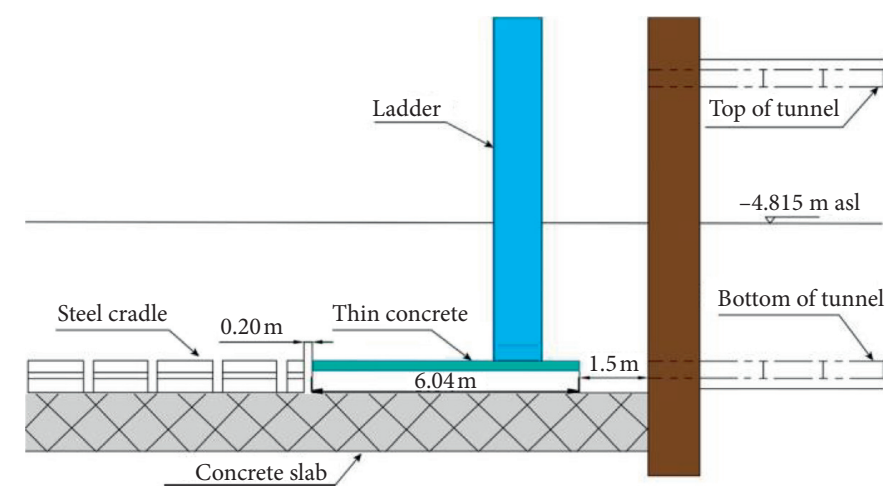

(b)

Figure 8: Design of the concrete cradle: (a) front view of the cradle and (b) side view of the cradle.

any dregs in the chamber were cleaned. Then, the screw conveyor gate was closed, and the sealing condition was checked. If there was any water leakage, polyurethane was quickly injected for sealing. To ensure that the chamber was not filled with concrete during the last $50 \mathrm{~cm}$ propulsion process, two pressure relief holes measuring $45 \times 45 \mathrm{~cm}$ were drilled within the cutting range of the diaphragm wall to a depth of $40 \mathrm{~cm}, 2 \mathrm{~m}$ above the bottom of the cutterhead. Without these holes, the shield thrust may increase to beyond the design bearing capacity of the underground diaphragm wall, resulting in excessive deformation of the diaphragm wall. The distribution of the holes is shown in Figure 9.

4.3. Sealing Control. To ensure adequate portal sealing, a sealing steel ring was fixed on the underground diaphragm wall of the receiving end and eight grouting holes were arranged along the annular direction of the steel ring. Each grouting hole was connected to the grouting pipeline and numbered to facilitate grouting. The gap between the sealing ring and the underground diaphragm wall was sealed by foam sealant to ensure close packing. Divers were employed to observe the portal sealing and, if a leakage was found, binary slurry or polyurethane was injected immediately to plug it. The arrangement of the sealing steel ring and pipeline is shown in Figure 10. The turning plate of the steel ring was fixed at the intersection position by steel wire rope, which could be easily placed under tension. Additionally, one end of the steel rope was connected with a manual chain hoist. When the cutterhead was aligned with the diaphragm wall at the front, the cutterhead was stopped. The thickness of the cutterhead was approximately $70 \mathrm{~cm}$; when the cutterhead passed the second rubber curtain at approximately $80-90 \mathrm{~cm}$, the steel wire rope was pulled tight to ensure that the rubber plate of the curtain was pressed tightly against the shield body. The tensioning of the wire rope is carried out by means of a tensioner installed in the shaft (about $5.0 \mathrm{~m}$ above the shield tunnel). The tensioner is connected to the wire rope that controls the rubber sheet.

Sealing the shield tail is also important for underwater shield recovery and requires special treatment [27]. First, the shield tail was injected with high-density and high-viscosity sealing grease. Second, the consistency of synchronous grouting slurry was increased, and the initial setting time of the slurry was shortened. Third, in order to improve the sealing performance of the tail brush, highly elastic steel wire balls were inserted into the tail of the shield ahead of time, and grease was applied artificially, as shown in Figure 11. Finally, emergency sealing materials and grouting equipment were prepared in the tunnel.

\subsection{Parameter Control during Shield Construction.} During the process of shield advance, if the thrust is too large, deformation of the underground diaphragm wall will be excessive and lead to damage of the wall. The maximum load the wall can receive while still withstanding deformation is $9000 \mathrm{kN}$; and the water injected into the shaft can provide an extra $3000 \mathrm{kN}$ of deformation resistance for the wall. Therefore, during excavation, the thrust should not exceed $12000 \mathrm{kN}$ but should not be less than $4351.77 \mathrm{kN}$, which is calculated theoretically. The penetration of the cutterhead was limited to $3 \mathrm{~mm} / r$ and the speed of cutterhead was limited to $1 \mathrm{r} / \mathrm{min}$. The wall had to be "excavated," not pushed, to avoid breaking large parts of the concrete around the machine and damaging the sealing ring. The normal driving thrust during construction is $25000-30$ $000 \mathrm{kN}$; however, as the shield approached the underground diaphragm wall, the driving thrust gradually decreased. The driving thrust in the underground diaphragm wall was approximately $5000 \mathrm{kN}$, which agreed with the calculation of the breakthrough resisting force mentioned previously. The thrust of the last 15 rings during the actual recovery process is shown in Figure 12.

4.5. Grouting Control. During shield advance, high viscosity bentonite slurry (fluidity $>90 \mathrm{~s}$ ) was injected into the periphery of the shield through the radial holes at the shield shell to fill the excavation gap and prevent sand from entering the shaft [28]. If necessary, bentonite can be replaced with acrylate gel for injection. After the last permanent ring was assembled, two additional temporary rings were assembled to push the shield out of the sealing ring. As the shield tail left the diaphragm wall, the annular space between 


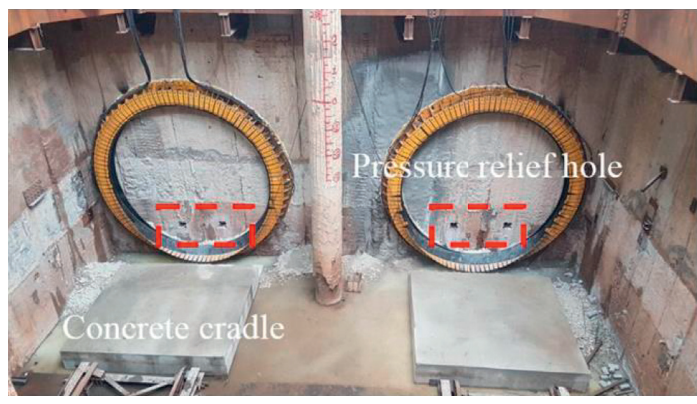

(a)

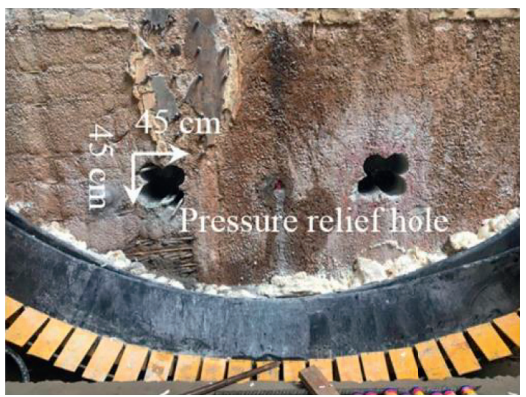

(b)

Figure 9: Distribution of pressure relief holes: (a) overall view and (b) partial view of pressure relief holes.

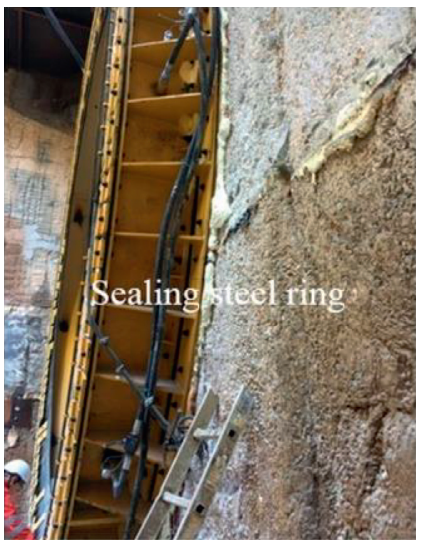

(a)

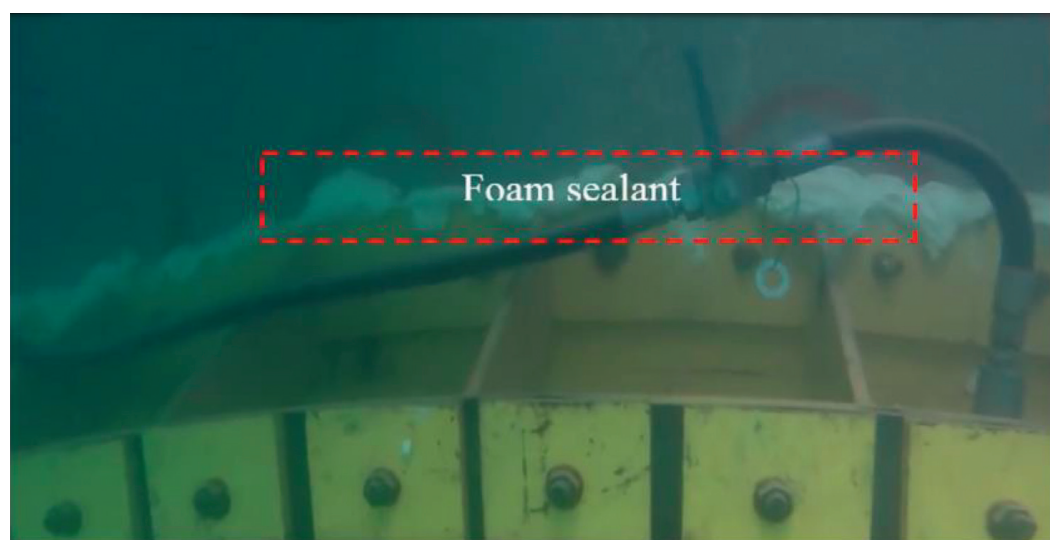

(b)

Figure 10: Portal sealing: (a) installation of the sealing steel ring and (b) foam sealant between the steel sealing ring and the underground diaphragm wall.

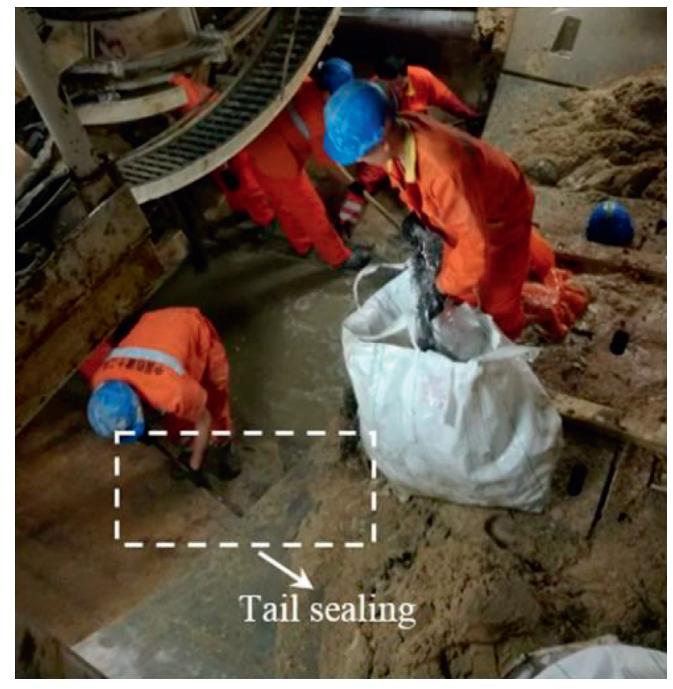

(a)

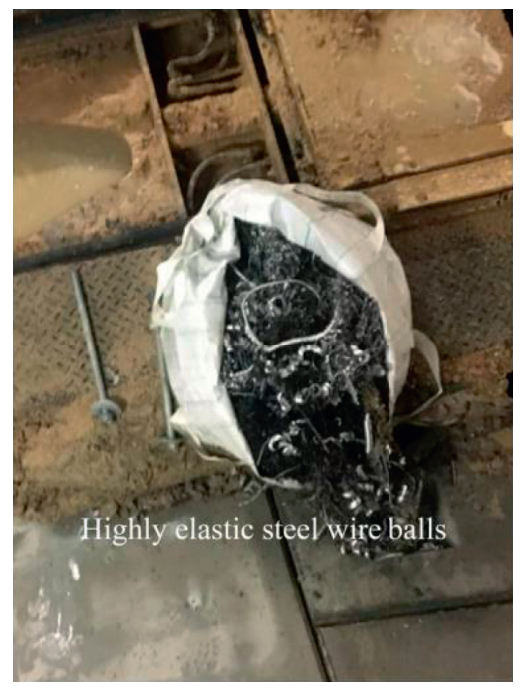

(b)

FIGURE 11: Shield tail sealing: (a) highly elastic steel wire balls are manually inserted into the tail of the shield; (b) photograph of the highly elastic steel wire balls. 


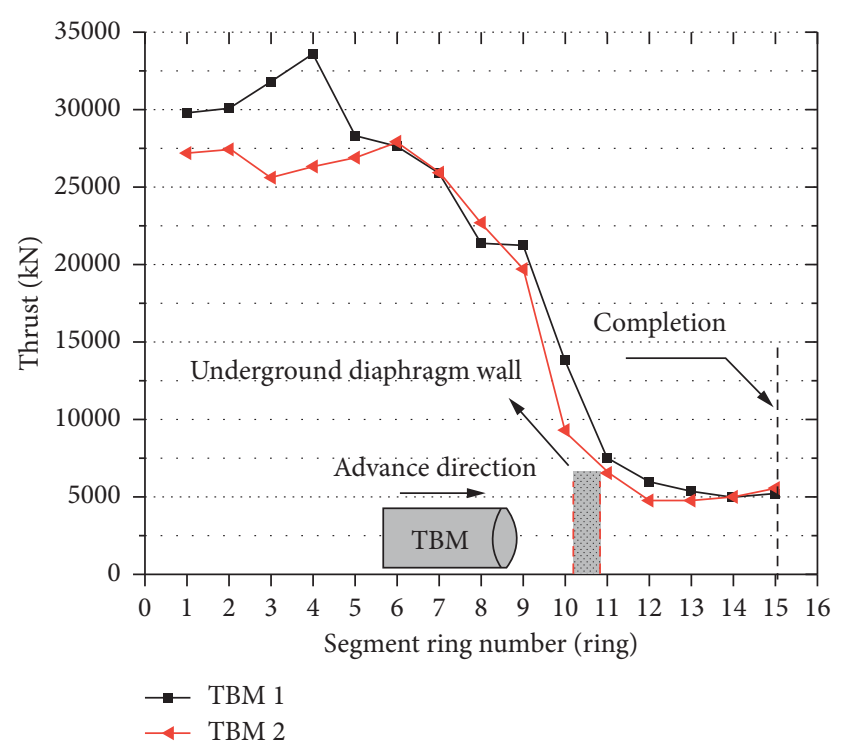

FIgURE 12: Thrust of the last 15 rings during shield recovery.

the segments and the wall was completely filled with synchronous grouting. In order to ensure the effectiveness of the grouting, after the completion of 24-hour synchronous grouting, a large amount of cement-sodium silicate binary slurry was injected through the reserved secondary grouting holes in the last five rings. The amount of slurry injected is shown in Figure 13. The synchronous grouting quantity was $5-7 \mathrm{~m}^{3} /$ ring. To prevent the segments from floating, the second grouting was conducted in the upper part of the tunnel on the last 15 rings within a range of $120^{\circ}$, and the second grouting amount was $0.5-0.7 \mathrm{~m}^{3} /$ ring. The ratio of binary slurry was $1: 1$ (volume ratio) and the initial setting time was $23 \mathrm{~s}$. The grout mixture is shown in Table 2. After $12 \mathrm{~h}$ of grouting, the sealing performance of the grouting was verified by drilling holes in the segments and checking for water flow.

4.6. Disc Cutter Maintenance. When the shield was situated at a maximum distance of $50 \mathrm{~m}$ from the diaphragm wall, a topographic survey was conducted to verify the accuracy of the heading and ensure that sufficient length would be available for possible corrections in the machine direction. Maintaining a vertical and horizontal attitude at $\pm 30 \mathrm{~mm}$, the actual attitude was measured once every 10 rings during tunneling and checked with the automatic steering system of the shield machine. If the attitude deviation was large, the direction adjustment was increased to provide enough space for deviation correction of the shield. When the shield was $20 \mathrm{~m}$ from the diaphragm wall, the chamber was opened with pressure to check and replace the disc cutters. If excessive wear was detected, the disc cutters were replaced with double-edged disc cutters containing an alloy to guarantee sufficient overcut so that the machine can advance through the concrete and to avoid the machine getting stuck on the concrete (Figure 14). A final survey was performed when the cutterhead was $5 \mathrm{~m}$ from the diaphragm wall to guarantee that the machine arrived within the tolerance range

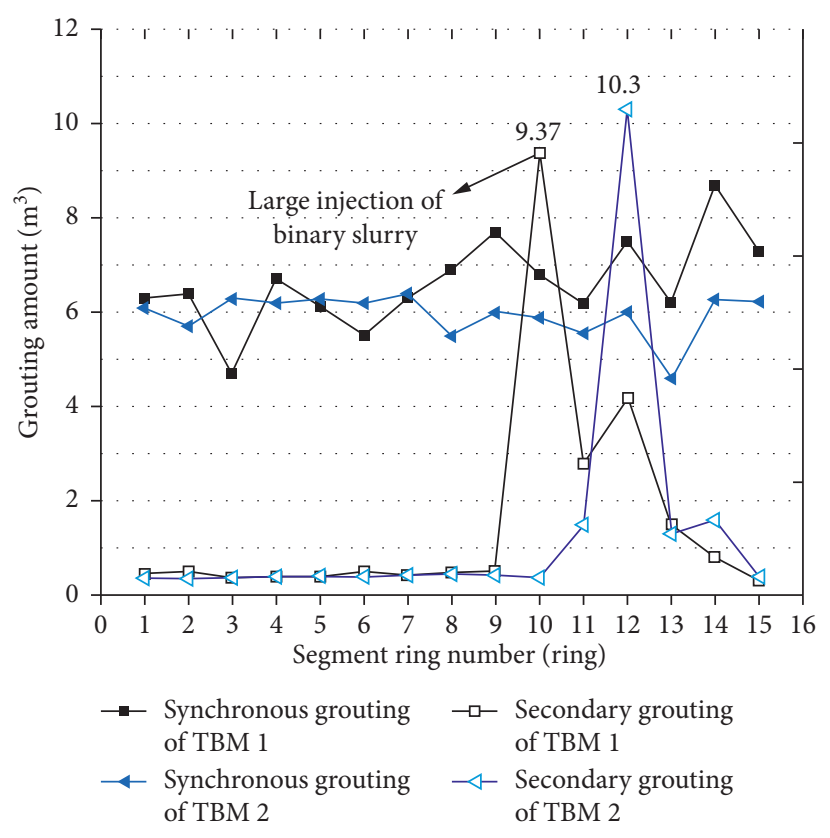

FIgURE 13: Amount of slurry injected into the last 15 rings.

TABLE 2: Ratio of binary slurry.

\begin{tabular}{lcc}
\hline Component & Composition & Volume (L) \\
\hline \multirow{2}{*}{ Cement slurry } & Cement & 50.00 \\
& Bentonite & 1.72 \\
& Water & 51.70 \\
\hline \multirow{2}{*}{ Sodium-silicate slurry } & Sodium silicate & 1.00 \\
& Water & 2.30 \\
\hline
\end{tabular}

$( \pm 30 \mathrm{~mm})$ of the designed tunnel axis. It was suggested that the machine advanced slightly above the designated elevation because the cutterhead has a tendency to fall during breakthrough.

In order to prevent the glass fiber-reinforced plastics from damaging the cord rubber plate, it is necessary to control the penetration depth and speed of the cutterhead. Divers checked before the cutterhead broke through the wall but did not touch the rubber curtain. If there were glass fiber-reinforced plastics inserted into the curtain, they and any concrete fragments were quickly removed. When there was a large block of concrete in front of the cutterhead, it was removed by a crane and the concrete inside the waterproof curtain was cleaned, as shown in Figure 15.

4.7. Shield Recovery and Drainage. After each ring was excavated, a diver observed the position of the shield machine and checked whether there was slurry flowing into the shaft through the sealing ring. As the setting time of the grout was $8 \mathrm{~h}$, the excavation speed of the last few rings had to be limited to a minimum of $4 \mathrm{~h}$ per ring to ensure grout solidification. After the last permanent ring was built with its face close to the inner face of the diaphragm wall, two additional temporary rings were installed in order to push the shield out of the rubber ring seal. When the grouting 


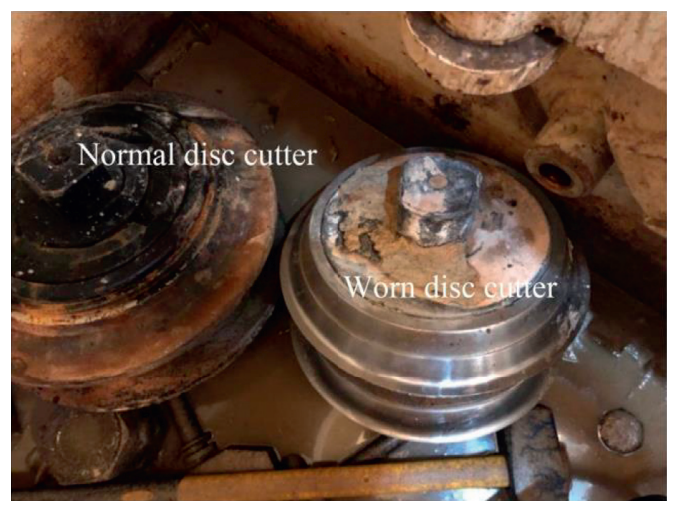

(a)

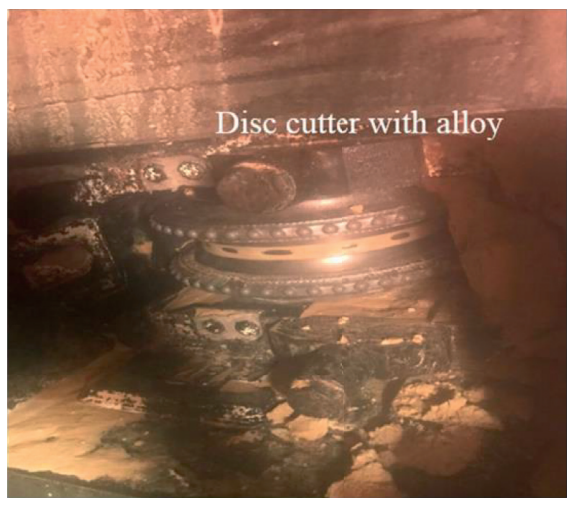

(b)

FIGURE 14: Replacement of worn disc cutters: (a) comparison of normal and worn disc cutter and (b) replacement disc cutter containing an alloy.

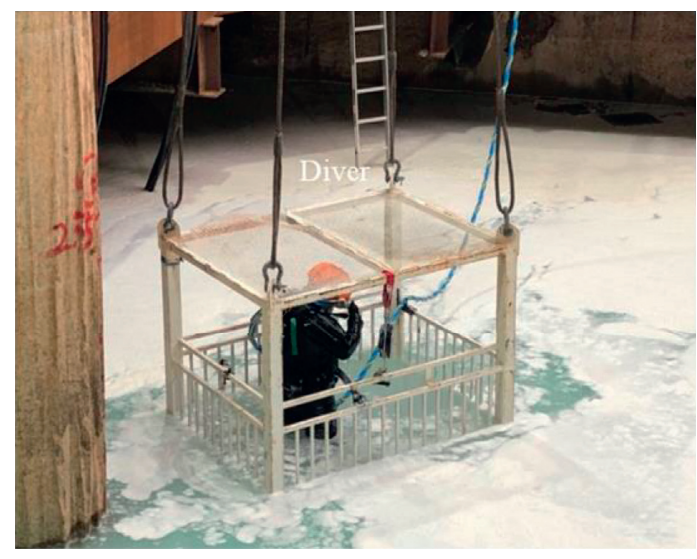

(a)

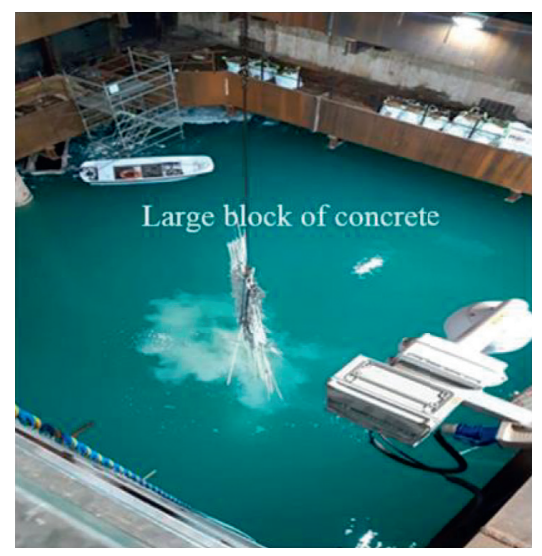

(b)

FIGURE 15: Removal of glass fiber-reinforced plastic and concrete: (a) using divers to cut off glass-fiber reinforced plastics and (b) using a crane to remove large blocks of concrete.

effect was confirmed to meet the requirements, the water in the shaft was pumped out. During the drawdown, the diver verified if there was groundwater flowing through the ring gap. For verification of inflows, pumping was performed at intervals of 1 or $3 \mathrm{~m}$ with holding times of $30 \mathrm{~min}$. If inflow was observed, polyurethane was injected through the first temporary ring and secondary injections were performed in the final two permanent rings from inside the tunnel. To ensure that the gap was filled, the grout had to overflow through the relief hole of the sealing ring. After drainage was completed, the two temporary rings (apart from the invert segments) were removed by the segment erector. After the shield was fully pushed onto the steel cradle, it was slid to the disassembly position under the opening in the roof before finally being recovered, as shown in Figure 16. The shield tunnel portal was fully sealed, and emergency measures were also set up to mitigate the risk of instability in the shaft. There were 16 grouting pipelines installed on the sealing steel ring of the tunnel portal, which could seal the tunnel portal in emergency. The design bearing capacity of the diaphragm wall was large enough so that after the water was pumped out from the shaft, the risk factors were controllable.

\section{Discussion}

5.1. Comparison of Different Methods. In this project, it took 25 days from the preparation period to the completion of underwater shield recovery as shown in Table 3 . This method is suitable for shafts that do not have suitable conditions for end reinforcement owing to site constraints and that have strata with a degree of self-stabilization. The method of end reinforcement is often used in shield recovery, but the amount of time required for end reinforcement is large. Sometimes, due to site conditions, it is impossible to reinforce the receiving end. If end reinforcement is not possible, shield recovery with a steel sleeve can be used, or underwater recovery of the shield can be performed by filling water into the receiving shaft. In this paper, various methods of shield recovery are compared as shown in Table 4. 


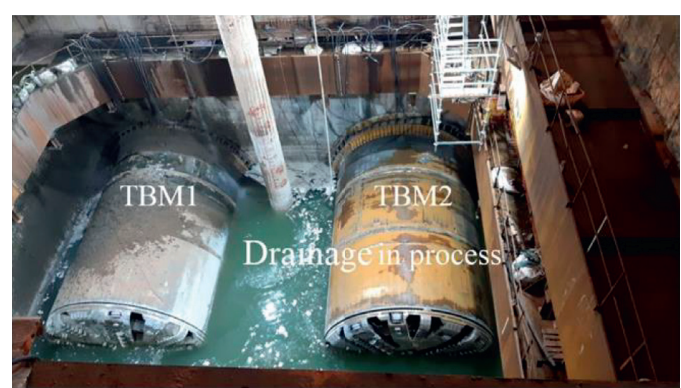

(a)

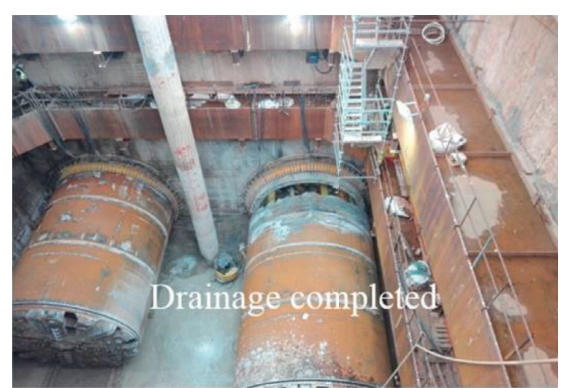

(b)

FIGURE 16: Completion of shield recovery: (a) drainage of the shaft and (b) recovery of the tail of the shield from the portal.

TABLE 3: Underwater recovery schedule of shield.

\begin{tabular}{lcc}
\hline Step & Process & Duration $(d)$ \\
\hline 1 & Sealing ring installation & 4 \\
2 & Concrete cradle casting & 2 \\
3 & Steel plate and weld placement \\
4 & Receiving bracket installation & 4 \\
5 & Grouting pipe installation for sealing ring & 3 \\
6 & Water injection into the shaft & 1 \\
7 & Underground diaphragm wall excavation & 2 \\
8 & Bottom concrete examination and clearing by divers & 1 \\
9 & Cutterhead excavation to the shield tail into the diaphragm wall \\
10 & Shield tail sealing \\
11 & Secondary grouting \\
12 & Shaft drainage & 2 \\
13 & Shield advancement to the designated position & 2 \\
\hline
\end{tabular}

However, for this project, underwater recovery was the best method.

5.2. Analysis of Construction Effect. There were several total stations set near the receiving shaft to monitor the surface settlement of the ground and the deformation of the diaphragm wall. There were eight monitoring points, composed of small prism on the ground surface and seven prisms on the underground diaphragm wall, as shown in Figure 17(a). The monitoring results indicate that when the first shield machine fully entered the shaft, the maximum surface settlement value was $4.26 \mathrm{~mm}$, located near the edge of the first tunnel, as shown in Figure 17(b). The water level in the shaft was higher than the initial level. During the recovery process of the first shield machine, the shield excavation gap was fully filled, and very little sand flowed in from the surrounding ground. The divers found only a small amount of concrete debris at the bottom of the underground diaphragm wall and did not observe large deformation of the wall. Considering that the water level in the shaft was still higher than the groundwater level, there was no need to inject more water into the shaft before the second shield was recovered. When the second shield machine advanced into the shaft, the maximum surface settlement was $8.8 \mathrm{~mm}$, located between the two tunnels. There was no leakage in the tunnel and no large dislocation or floating of segments, and deformation of the diaphragm wall was less than $4 \mathrm{~mm}$.

The double-liquid grout injected in the last several ring segments from the tunnel portal played an important role in sealing the tunnel against the water, which showed that the mix ratio and grouting amount of the double liquid grout were appropriate. With drilling holes in the last few ring segments, no water leakage was observed in the holes, indicating that the excavation gap was fully filled with grout. The shield attitude control was accurate, and the cutterhead did not touch the sealing steel ring of the tunnel portal. Fortunately, the portal did not leak; hence, the 16 grouting pipelines on the portal sealing steel ring were not used. The screw conveyor of the shield machine was well sealed and there was no spewing. The cutterhead was successfully driven into the diaphragm wall and the concrete cradle, thanks to the maintenance and replacement of the cutter tool. The successful application of the pressure relief holes kept the thrust of the shield within the proper range and did not damage the diaphragm wall. The qualitative observations and measurements indicate that the sealing method was effective, and the concrete cradle design and pressure relief holes were useful for shield recovery. In future practical applications, the concrete cradle used to adjust the attitude of shield machine should adopt low-grade concrete not exceeding B20. To ensure safety, emergency grouting 
TABle 4: Comparison of different methods of shield recovery.

\begin{tabular}{lll}
\hline Recovery method & Applicable strata & Application effect \\
\hline
\end{tabular}

(1) Little soil disturbance; (2) no joint in the whole length of pile with full Deep mixing Silt, sandy soil, silty mixing of cement and soil; (3) good cement pile soil, peat soil water sealing performance; (4) little environmental pollution, noise, and vibration during construction.

High-pressure Silt, sandy soil, silty rotary jet grouting pile

soil, loess, plain fill

(1) Small footprint; (2) little vibration and noise; (3) potential for environmental pollution.

(1) High strength of soil

Shield recovery with receiving end reinforcement

Freezing

Water bearing strata reinforcement; (2) good water sealing performance; (3) no environmental pollution.

Rodin jet pile
method

Metro jet system method

Steel sleeve

Shield recovery with no receiving end reinforcement

$\begin{array}{cc}\text { Underwater } & \text { Water bearing strata } \\ \text { with high } \\ \text { recovery }\end{array} \quad \begin{gathered}\text { permeability and } \\ \text { bearing capacity }\end{gathered}$

\section{Various strata and complex site} environment

Various strata and complex site environment

Strata with high permeability and water content

(1) Large pile diameter; (2) pile of good quality; (3) small footprint; (4) low environmental impact.

(1) Large pile diameter; (2) pile of good quality; (3) small footprint; (4) low environmental impact.

(1) Safe construction; (2) short construction period; (3) reusability.

(1) Short construction period;

(2) environmental protection;

(3) small environmental impact. Evaluation

(1) Large site area required; (2) poor reinforcement effect when reinforcement depth is more than $15 \mathrm{~m}$.

(1) Good control of position and scope of slurry injection; (2) tight connection between piles.

(1) Good strength and impermeability of soil is good, making it a relatively safe construction method; (2) produces a frost heaving and melting sinking effect, which has a great influence on the surrounding area; (3) long construction period and high cost.

(1) Guaranteed reinforcement quality with large depth; (2) high construction efficiency and low cost.

(1) Complex construction technology and low construction efficiency; (2) high construction cost.

(1) Wide applicability; (2) avoids pipeline relocation; (3) provides environmental protection.

(1) Suitable for shafts that do not allow for end reinforcement owing to site constraints and that have strata with a degree of selfstabilization.

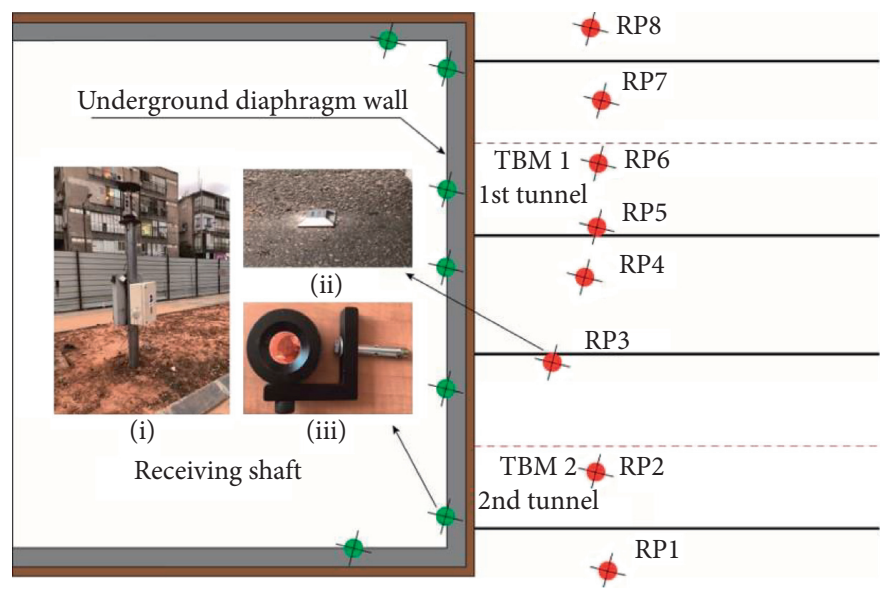

(a)

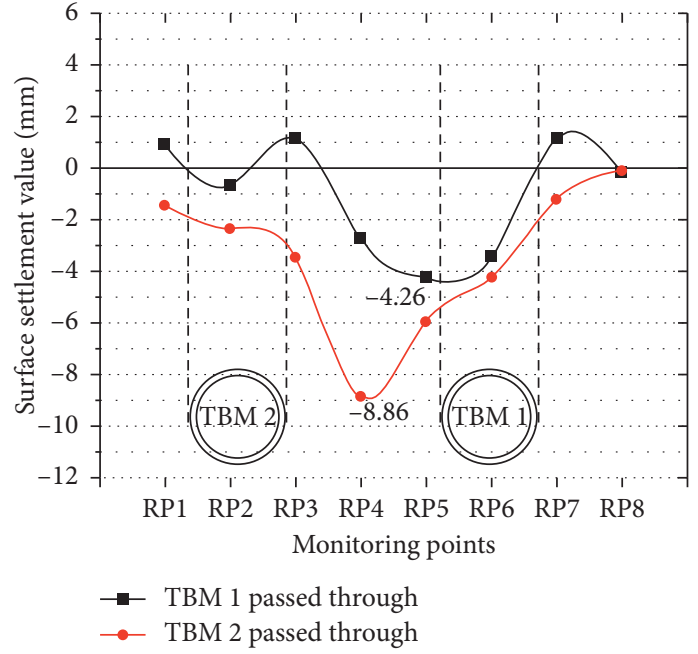

(b)

FIGURE 17: Monitoring and analysis of surface subsidence: (a) distribution of monitoring points (i) total station, (ii) prism on the ground surface, and (iii) prism on the diaphragm wall); (b) surface subsidence curve. 
machines and polyurethane should be prepared on the surface of the shaft.

\section{Conclusions}

Under the condition of zero end reinforcement, two EPB shield machines were successfully recovered underwater using a novel recovery method involving injection of water into the receiving shaft. The entire recovery process was verified to be safe and controllable. Various risk mitigation techniques were employed, which provide valuable insights for shield recovery in similar construction projects. Based on a theoretical analysis and practical observations, the following conclusions were drawn:

(1) During the actual construction project, the water injected into the shaft was sufficient to withstand the water pressure in the surrounding strata. From the beginning of the excavation of the underground diaphragm wall by the shield cutterhead to the entry of the shield tail into the rubber curtain, the diver needs to dive down to check the position and seal of the shield machine for each advance.

(2) The thrust of the shield breaking through the diaphragm wall should not exceed $12000 \mathrm{kN}$, and the penetration of the cutterhead should be limited to less than $3 \mathrm{~mm} / r$. Before the shield breaks through the diaphragm wall, axis measurement should be performed and disc cutters with worn edges should be replaced.

(3) Due to deviation of the shield attitude, it was difficult to recover the shield directly using steel brackets. By creating a transitional area to adjust the shield attitude, the proposed concrete cradle ensured that the shield was pushed smoothly onto the steel cradle. Pressure relief holes set into the underground diaphragm wall reduced the pressure of the shield chamber and prevented deformation of the diaphragm wall caused by an excessive thrust force.

(4) Installation of a sealing steel ring with grouting pipelines is effective for portal sealing. When the cutterhead excavated the diaphragm wall, high-viscosity bentonite injected into the chamber not only filled the excavation gap but also formed a mud film that reduced permeability. A large amount of binary slurry was injected to form a water stop ring, which effectively reduced the risk of water inflow and sand gushing.

\section{Data Availability}

The data used to support the findings of this study are available from the first author upon request.

\section{Conflicts of Interest}

The authors declare that they have no conflicts of interest.

\section{Acknowledgments}

This study was supported by the National Natural Science Foundation of China (Grant no. U1261212). Assistance by An Hongbin from the 2nd Engineering Co., Ltd. of China Railway 12th Bureau Group and Huai Pingsheng from the International Engineering Co., Ltd. of China Railway 12th Bureau Group is greatly appreciated.

\section{References}

[1] D. V. L. Hunt, L. O. Makana, I. Jefferson, and C. D. F. Rogers, "Liveable cities and urban underground space," Tunnelling and Underground Space Technology, vol. 55, pp. 8-20, 2016.

[2] P. P. Nelson, "A framework for the future of urban underground engineering," Tunnelling and Underground Space Technology, vol. 55, pp. 32-39, 2016.

[3] Q. H. Qiang, "Present state, problems and development trends of urban underground space in China," Tunnelling and Underground Space Technology, vol. 55, pp. 280-289, 2016.

[4] Z.-L. Chen, J.-Y. Chen, H. Liu, and Z.-F. Zhang, "Present status and development trends of underground space in Chinese cities: evaluation and analysis," Tunnelling and Underground Space Technology, vol. 71, pp. 253-270, 2018.

[5] J.-W. Zhao, F.-L. Peng, T.-Q. Wang, X.-Y. Zhang, and B.-N. Jiang, "Advances in master planning of urban underground space (UUS) in China," Tunnelling and Underground Space Technology, vol. 55, pp. 290-307, 2016.

[6] P. Perazzelli, T. Leone, and G. Anagnostou, "Tunnel face stability under seepage flow conditions," Tunnelling and Underground Space Technology, vol. 43, pp. 459-469, 2014.

[7] R.-p. Chen, J. Li, L.-g. Kong, and L.-j. Tang, "Experimental study on face instability of shield tunnel in sand," Tunnelling and Underground Space Technology, vol. 33, pp. 12-21, 2013.

[8] Y. Fang, Z. Chen, L. Tao, J. Cui, and Q. Yan, "Model tests on longitudinal surface settlement caused by shield tunnelling in sandy soil," Sustainable Cities and Society, vol. 47, p. 101504, 2019.

[9] J. Hu, W. Liu, Y. Pan, and H. Zeng, "Site measurement and study of vertical freezing wall temperatures of a large-diameter shield tunnel," Advances in Civil Engineering, vol. 2019, Article ID 8231458, 11 pages, 2019.

[10] Y. Li, S. Xu, H. Liu, E. Ma, and L. Wang, "Displacement and stress characteristics of tunnel foundation in collapsible loess ground reinforced by jet grouting columns," Advances in Civil Engineering, vol. 2018, pp. 1-16, Article ID 2352174, 2018.

[11] C. Guan and Y. Yang, "Field study on the waterstop of the rodin jet pile method in a water-rich sandy gravel stratum," Applied Sciences, vol. 9, no. 8, p. 1709, 2019.

[12] X. J. Wei, G. Wei, and J. Hong, "Study of analytical solution on starting shaft disaster in shield launching," Advanced Materials Research, vol. 261-263, no. 263, pp. 1475-1479, 2011.

[13] T. M. Wang and Z. R. Dai, "Application on ground reinforcement method of launching shaft for shield tunnel," Journal of Railway Engineering Society, vol. 31, no. 8, p. 90, 2014, (in Chinese).

[14] S. M. Liao, Y. Q. Men, G. Q. Zhao, and W. Z. Xu, "Mechanical behaviors and field tests of steel sleeves during shield receiving," Chinese Journal of Geotechnical Engineering, vol. 38, no. 11, pp. 1948-1956, 2016, (in Chinese).

[15] T. Funazaki and R. Matsumoto, "Construction of an undersea shield driven tunnel under high water pressure from a marine launching base," in Proceedings of the World Tunnel Congress “Tunnels and Metropolises", São Paulo, Brazil, April 1998. 
[16] J. Hu, J. Zhou, Y. Lin, L. Han et al., "The study on some new reinforcement methods for shield launching and arriving," in Proceedings of the 4th International Conference on Materials Engineering for Advanced Technologies (ICMEAT), pp. 94-98, London, England, UK, December 2015.

[17] Y. Liu, J. Hu, H. Xiao, and E. J. Chen, "Effects of material and drilling uncertainties on artificial ground freezing of cementadmixed soils," Canadian Geotechnical Journal, vol. 54, no. 12, pp. 1659-1671, 2017.

[18] J. Morey and D. W. Campo, "Quality control of jet grouting on the Cairo metro," Proceedings of the Institution of Civil Engineers - Ground Improvement, vol. 3, no. 2, pp. 67-75, 1999.

[19] Z. Ben, P. Yang, C. Chen, and S. Wang, "Water receiving technology of large slurry shield in river-crossing subway tunnel," Journal of Nanjing Forestry University (Natural Sciences), vol. 39, no. 1, pp. 119-124, 2015, (in Chinese).

[20] G. Li and H. Huang, "Risk analysis on arriving into shaft of super large diameter shield machine under water," Chin. Chinese Journal of Underground Space and Engineering, vol. 5, no. S1, pp. 1422-1426, 2009, (in Chinese).

[21] R. K. Pan, Y. D Jiang, and P. Yang, "Construction technologies of river-crossing tunnel using small-diameter EPB shield in watered sandy stratum," Journal of Railway Science and Engineering, vol. 14, no. 10, pp. 2185-2193, 2017, (in Chinese).

[22] Z.-S. Yang, F.-L. Peng, Y.-K. Qiao, and Y.-Y. Hu, "A new cryogenic sealing process for the launch and reception of a tunnel shield," Tunnelling and Underground Space Technology, vol. 85, pp. 406-417, 2019.

[23] G. Russo, A. Corbo, F. Cavuoto, and S. Autuori, "Artificial ground freezing to excavate a tunnel in sandy soil. measurements and back analysis," Tunnelling and Underground Space Technology, vol. 50, pp. 226-238, 2015.

[24] Z. Wu, C. Z. Geng, and L. Wang, "Underwater receiving technology of EPB shield in water-rich gravel stratum," Tunnel Construction, vol. 38, no. 12, pp. 2040-2045, 2018, (in Chinese).

[25] P. Yang, T. Zhang, and Y. Zhang, "Investigation of frostheaving characteristics of horizontal-cup-shape frozen ground surface for reinforced end soil mass in shield tunnel construction," Periodica Polytechnica Civil Engineering, vol. 61, no. 3, pp. 541-547, 2017.

[26] H. N. Wu, P. Zhang, R. P. Chen, X. T. Lin, and Y. Liu, "Ground response to horizontal spoil discharge jet grouting with impacts on the existing tunnels," Journal of Geotechnical and Geoenvironmental Engineering, vol. 146, no. 7, Article ID 05020006, 2020.

[27] F. Ye, N. Qin, X. Gao, X.-y. Quan, X.-z. Qin, and B. Dai, "Shield equipment optimization and construction control technology in water-rich and sandy cobble stratum: a case study of the first yellow river metro tunnel undercrossing," Advances in Civil Engineering, vol. 2019, Article ID 8358013, 12 pages, 2019.

[28] T. Kasper and G. Meschke, "A numerical study of the effect of soil and grout material properties and cover depth in shield tunnelling," Computers and Geotechnics, vol. 33, no. 4-5, pp. 234-247, 2006. 